\title{
Characterization of Postnatal Sodium Fluctuation in Very Preterm Neonates
}

(1) Department of Neonatology, University Children's Hospital Basel (UKBB), University of Basel, Basel, Switzerland

(2) Department of Pediatrics, University of Bern, Children's Hospital Inselspital Bern, Bern, Switzerland

(3) Pediatric Pharmacology and Pharmacometrics Research Center, University Children's Hospital Basel (UKBB), University of Basel, Basel, Switzerland

(4) Quantitative Solutions a Certara Company, Princeton, NJ, USA

\section{Background and Aims}

Large variations of serum sodium $(\mathrm{Na})$ are associated with increased morbidity and mortality in adults. However, evidence is low in pediatrics and even more so in preterm infants. We aimed to identify factors influencing $\mathrm{Na}$ fluctuations during the first 28 days of life in preterm infants $<32$ weeks gestational age (GA).

\section{Methods}

This retrospective study included all preterm neonates born 2007-2014 with GA $<32$ weeks or birth weight $<1500 \mathrm{~g}$ at the University Children's Hospital Berne, Switzerland.

Seven parameters were analyzed concerning their influence on Na variations: GA, delivery mode (spontaneous vs. Csection), small for gestational age $(<10$ th percentile), gender, antenatal steroids and birthweight.

Descriptive modelling included non-linear mixed modelling to fit data and to characterize covariate effects. Secondary parameters, such as predicted $\mathrm{Na}$ concentration, were accessed via simulations.

\begin{tabular}{|lcccccc|}
\hline Description & Unit & Mean & SD & Median & IQR & Min, Max \\
\hline Na at birth & $\mathrm{mmol} / \mathrm{L}$ & 133.2 & 2.0 & 133.3 & $\begin{array}{c}{[132.1,} \\
134.5]\end{array}$ & {$[124.4,138.7]$} \\
\hline Na peak & $\mathrm{mmol} / \mathrm{L}$ & 143.0 & 2.7 & 142.7 & $\begin{array}{c}{[141.1,} \\
144.6]\end{array}$ & {$[135.9,154.1]$} \\
\hline $\begin{array}{l}\text { Na at end of } \\
\text { observation }\end{array}$ & $\mathrm{mmol} / \mathrm{L}$ & 134.9 & 1.8 & 135.0 & $\begin{array}{c}{[133.8,} \\
136.0]\end{array}$ & {$[124.1,142.0]$} \\
\hline $\begin{array}{l}\text { Time of Na } \\
\text { increase }\end{array}$ & days & 1.31 & 0.53 & 1.21 & {$[1.00,1.48]$} & {$[0.44,7.08]$} \\
\hline $\begin{array}{l}\text { Time of Na } \\
\text { peak }\end{array}$ & days & 2.95 & 0.56 & 2.85 & {$[2.60,3.15]$} & {$[1.80,8.65]$} \\
\hline
\end{tabular}

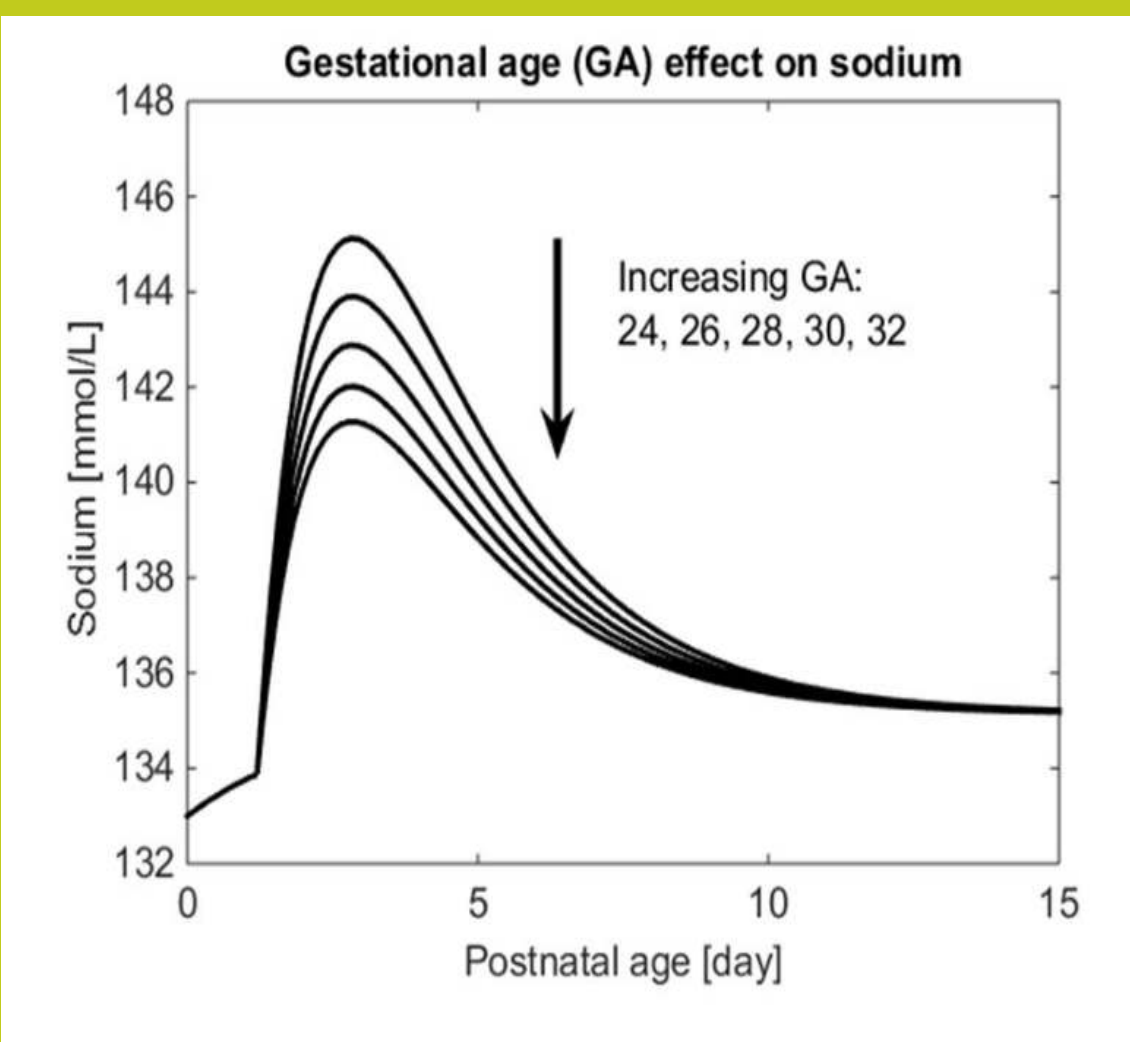

\section{Results}

A total of 901 preterm neonates with GA of 29.4 [interquartile range $27.4,30.9$ ] weeks and a total of $20714 \mathrm{Na}$ measurements were eligible.

$\mathrm{Na}$ at birth was $133.2( \pm 2.0) \mathrm{mmol} / \mathrm{l}$ and similar across patient groups. $\mathrm{Na}$ increase started at postnatal age (PNA) of $1.31( \pm 0.53)$ days and a Na peak of $143( \pm 2.7) \mathrm{mmol} / \mathrm{l}$ was observed at $2.95( \pm 0.56)$ days.

Neonates with a GA below 25 weeks had an Na peak concentration of $146.0( \pm 3.5) \mathrm{mmol} / \mathrm{L}$ whereas neonates with GA equal or above 31 weeks had a significantly ( $p<$ $0.0001)$ lower peak of $142.0( \pm 2.1) \mathrm{mmol} / \mathrm{L}$.

After vaginal delivery $(n=154)$ preterm infants experienced a significantly $(p<0.0001)$ higher Na peak concentration $144.1( \pm 2.5) \mathrm{mmol} / \mathrm{L}$ than those delivered by $\mathrm{c}$-section $142.7( \pm 2.7) \mathrm{mmol} / \mathrm{L}(\mathrm{n}=689)$.

Preterm infants born SGA $(n=122)$ had a significantly $(p<$ 0.0001 ) lower $\mathrm{Na}$ peak concentration of $141.9( \pm 2.7)$ $\mathrm{mmol} / \mathrm{L}$ compared to infants not being SGA $143.2( \pm 2.7)$ $\mathrm{mmol} / \mathrm{L}(\mathrm{n}=721)$.

After 10-15 days mean $\mathrm{Na}$ concentration was constant around $134 \mathrm{mmol} / \mathrm{l}$. Antenatal steroids, gender and birthweight did not have an influence on sodium at baseline or peak sodium.

Interestingly, neither time of $\mathrm{Na}$ increase nor $\mathrm{Na}$ peak concentration were influenced by any of the assessed parameters.
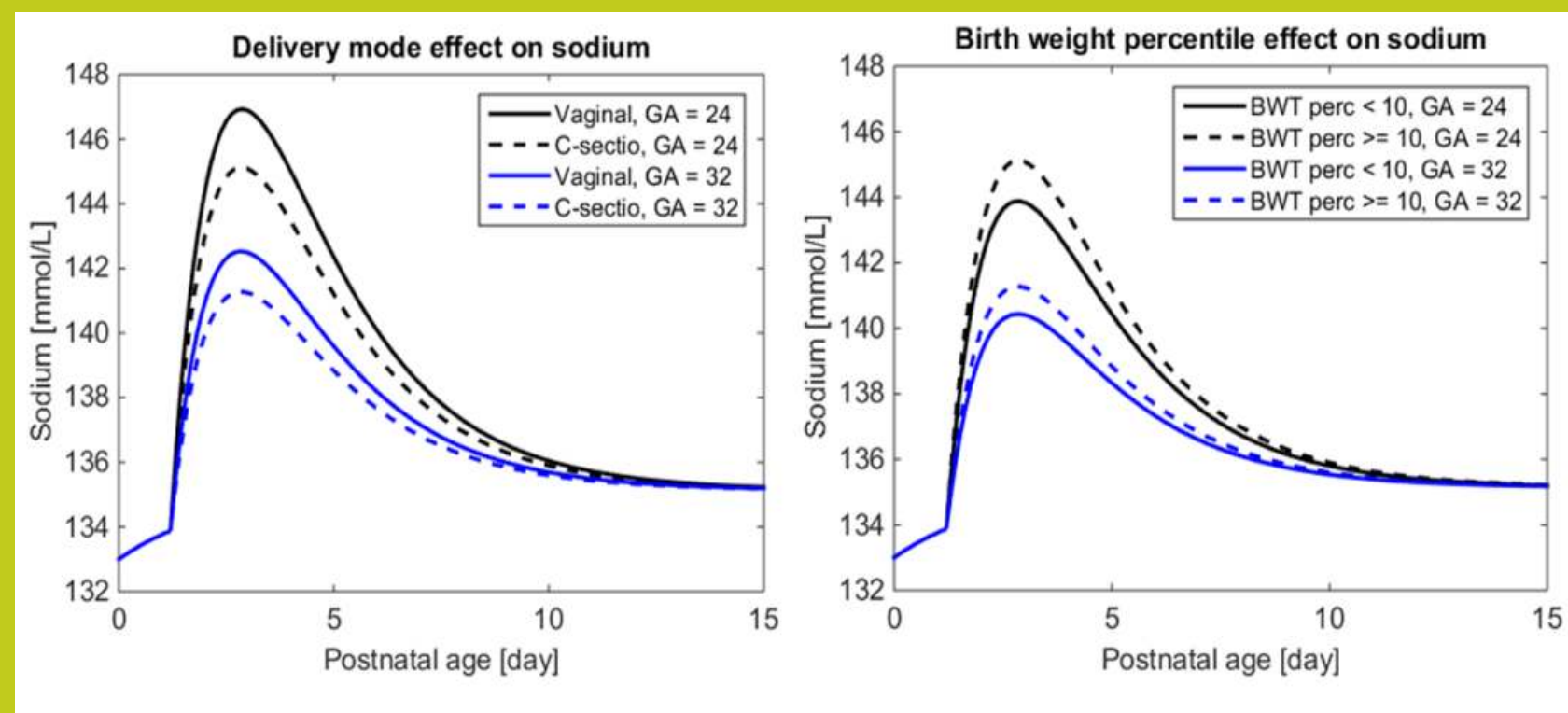

Conclusion

$\mathrm{Na}$ fluctuations were increased in patients with decreasing GA, spontaneous delivery or decreased birthweight percentile, while gender, antenatal steroids and birthweight showed no significant effect.

Modeling and simulation allowed to characterize individual serum sodium profiles and to identify risk factors in this very vulnerable population. 